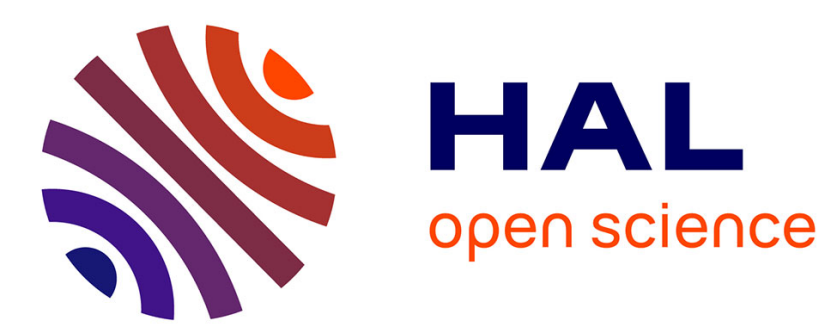

\title{
Recognition within the decision-making process: A case study from expert volleyball players
}

\author{
Anne-Claire Macquet
}

\section{To cite this version:}

Anne-Claire Macquet. Recognition within the decision-making process: A case study from expert volleyball players. Journal of Applied Sport Psychology, 2009, 21 (1), pp.64-79. 10.1080/10413200802575759 . hal-01713145

\section{HAL Id: hal-01713145 \\ https://hal-insep.archives-ouvertes.fr/hal-01713145}

Submitted on 20 Feb 2018

HAL is a multi-disciplinary open access archive for the deposit and dissemination of scientific research documents, whether they are published or not. The documents may come from teaching and research institutions in France or abroad, or from public or private research centers.
L'archive ouverte pluridisciplinaire HAL, est destinée au dépôt et à la diffusion de documents scientifiques de niveau recherche, publiés ou non, émanant des établissements d'enseignement et de recherche français ou étrangers, des laboratoires publics ou privés. 


\section{Recognition within the decision-making process:}

\section{A case study from expert volleyball players}

Running head: Decision-making in expert volleyball players

\section{Author :}

A.C. MACQUET

\section{Affiliation :}

Institut National du Sport et de l’Education Physique, Paris, France

Correspondance concerning this article should be adressed to Anne-Claire Macquet, Laboratoire de Psychologie et d’Ergonomie du Sport

Institut National du Sport et de l'Education Physique

11 avenue du Tremblay 75012 Paris

France

e-mail : anne-claire.macquet@insep.fr

tel number: (33 1) 41744577

Fax number (33 1) 41744535 


\begin{abstract}
This article reports on decision-making under time pressure conditions. It aims at testing the Recognition-Primed Decision model with regard to volleyball. Seven male expert players participated in this study. A match was videotaped; each player was interviewed in a self-confrontation interview. Inductive and deductive analysis revealed three main results. The first showed that their decision-making was based on a recognition process of the situation typicality. The second emphasized that this process had four by-products: (a) expectations, (b) relevant cues, (c) plausible goals and, (d) typical action. The players did not equally report these by-products. The third main result showed that the decisions were largely prearranged, they consisted of an association between a typical situation and a typical action, the typical action was then adapted to the current situation. The results are discussed in relation to the Recognition-Primed Decision model and to research that has considered decision-making.
\end{abstract}


Recognition within the decision-making process:

A case study from expert volleyball players

In sport, decision-making is important for athletes, who have to make the right decisions in a short time frame. Regarding sport, various studies have focused on different aspects of decision-making. They have referred to visual search strategies (e.g., Farrow \& Abernethy, 2003; Salvesbergh, Williams, Van Der Kamp, \& Ward, 2002), knowledge bases (e.g., McPherson \& Kernodle, 2003; Williams \& Davids, 1995), the role of practice in decision-making (e.g., Kibele, 2006; Poolton, Masters, \& Maxwell, 2006; Raab, 2002, 2003), and the option generation process (e.g., Johnson \& Raab, 2003). These studies, apart from that of McPherson and Kernodle (2003), used standardized or simulated situations. These situations allowed for the reduction of the factor of uncertainty to control the studied variables. Their context was different from that of competitive situations. In competitive situations, uncertainty cannot be controlled by the researchers. Other studies concern the ecological dynamic of decision-making in sport (Araujo, Davids, \& Hristovski, 2006).

In reference to the theoretical approach of the course of action (Theureau, 1992), studies have focused on the athletes' activity. This approach postulates that affective and cognitive processes cannot be separated from the situations as they develop. Activity is considered as a meaning construction process: meaning is built as activity unfolds, it does not precede it. These studies focused on: (a) the interpretation of athlete particular situation during the course of action (e.g., Arippe-Longueville, (d'), Saury, Fournier, \& Durand, 2001), (b) the knowledge produced during the course of action (e.g., Sève, Saury, Ria, \& Durand, 2003), (c) the time duration in a competition during which athletes can observe, and adapt their actions to those of their opponent's (e.g., Sève \& Poizat, 2005), and (d) the problems 
encountered by athletes during their performances (Haw \& Durand, 2007). These studies focused on dynamic and natural situations.

These studies and that of McPherson and Kernodle (2003) depended on the assumption that skilled performers usually make their decisions in a conscious way and they are able to reliably verbally report them to others. This assumption has been controversial. Nisbett and Wilson (1997) considered that people cannot completely and accurately report their higher order mental processes. Ericsson and Simon $(1980,1993)$ considered that retrospective verbalization only allows one to verbalize the products of this activity (the reasons). In sports, Raab (2003) and Poolton et al. (2006) suggested that acquiring decisionmaking requires both implicit and explicit processes and verbal reports on implicit processes lag behind what is done and known unconsciously.

The methodological framework of retrospective reports is concerned with qualitative methodologies and a first person approach (Varela \& Shear, 1999). The player reenacts his/her activity in the course of action in its natural setting, without disturbing the performance. Retrospective reports take place after the competition and are concerned with the evolution of particular behaviors and psychological components such as focus, meanings and emotions in competitive situations. This method aims to study problems encountered by athletes, and the methods that are used to cope with them.

In dynamic sports, time constraints present a conflict; athletes must act quickly even though they cannot rapidly understand a given situation. These difficulties in understanding are linked to the uncertainty of the situation (e.g., locus, time, nature of the event) and to the short duration of the event. Some information is not available quickly enough, although this information seems important for the athletes to assess the situation and therefore make and carry out a decision. Athletes have to resolve a dilemma: waiting for useful information and accepting the risk of not having enough time to act, versus anticipating a decision and 
accepting the risk of putting into action a decision that is not adapted to the given situation. In dynamic situations, time-pressure seems to be too great to allow the player to understand all the aspects of the situation (Amalberti, 2001, 2003). To cope with time-pressure, athletes have to be content with a partial and sufficient understanding of a given situation to have time to act. They are trained to reproduce efficient actions, but are sometimes overloaded with information and have difficulty accommodating their actions because of time constraints. Time to react is critical in sport. For example, in volleyball, five players can potentially attack the ball in different places and time frames (Blain, 2006). The receiver has to quickly determine where, to whom , when, and what sort of set the hitter is going to hit to predict where, when and who is going to receive the hit. The number of attack options increases with the accuracy of the initial pass. The receiver has to reduce this complexity and cope with time pressure.

Most competitive situations in sport present many similarities to dynamic situations studied using the Naturalistic Decision-Making (NDM) approach (e.g., Salas \& Klein, 2001; Zsambok \& Klein, 1997). These situations contain ill-structured problems and time pressure, and refer to an uncertain dynamic environment, with shifting, ill-defined or competing goals, action/feedback loops, many players, and high stakes. Like competitive sport situations, they refer to the real context of work. NDM has been used to study decision-making in many areas, such as nuclear power (e.g., Roth, 1997), aviation (e.g., Kaempf \& Orasanu, 1997), military command and control (e.g., Pascual \& Henderson, 1997), and health care (e.g., Keyser (de) \& Nissen, 2001). Regarding sport and the NDM approach, we are aware of only two studies that focused on decision-making in competitive situations. Omodei, McLennan, and Withford (1998) adopted a debriefing procedure to provide a method to focus on the mental aspects of athletes' performance, that can be used by coaches to enhance performance. Macquet and Fleurance (2007) studied decision-making in expert badminton players. They emphasized 
different types of decisions made in relation to the game and they generated information and knowledge categories associated with the types of decisions made. NDM focuses on the way people use their experience to make decisions during their work and aims at improving this process of decision-making. During the training process, athletes over-train decision-making and application of actions to rapidly make and carry out an efficient decision. During competitions, coaches expect athletes to make decisions that have been learned during the training process. These decisions are expected to be efficient and to control the situation. But how do athletes really make their decisions in competition?

In NDM, Klein (1997) developed a model of decision-making for experienced agents involved in dynamic and complex situations, who cope with personal consequences for their actions. His model is known as Recognition-Primed Decision (RPD). It aims to describe how people can use their experience to make good decisions without needing to compare the multiple alternative courses of action. This model differs from Rational Choice models (e.g., Simon, 1956). “Experienced agents use their experience to identify a workable course of action as the first one they consider.” (Klein, 1997, p. 287). If they have to evaluate it, they mentally simulate it to see if it would work. The RPD model suggests that people can assess the given situation by recognizing its typicality. The decision maker recognizes the situation through salient features that experience has shown to be useful. Recognition has four byproducts: (a) expectancies, (b) relevant cues, (c) plausible goals, and (d) typical action.

There are three levels in experiencing the situation in a changing context: simple match, diagnose the situation, and evaluate a course of action. In level 1 , the situation is rapidly perceived as typical, so the decision maker can quickly implement a course of action that corresponds to this typical situation. In level 2, the situation is not perceived as typical at first, so the decision maker has to clarify it by diagnosing it, to emphasize its typicality. Then, he/she can implement a course of action based on a typical action. In level 3, the decision 
maker perceives the situation as typical. Before implementing a typical action, he/she investigates several actions, evaluates them through mental simulation to perceive if they will work or not. When he/she considers that it will work, he/she implements it. However, decision makers spend more time and energy assessing what is happening rather than comparing several courses of action.

According to NDM, decision makers determine only a few options (Johnson \& Raab, 2003; Klein, Wolf, Militello, \& Zsambok, 1995), and most often, they determine only one (Yates, 2001). Implicitly, the decision-making process is based on the use of "rules"; the decision maker applies a rule in the form "if condition C holds, then take action A". The given situation is compared to a typical situation contained in his/her memory that is associated with a typical action. If the given situation is analogous to the typical situation contained in memory, then the decision maker knows what to do and can carry out the corresponding action. Observation of volleyball players' actions suggests that the players reproduce actions in a competitive context that have been over-trained during practice. The NDM approach and more specifically the RPD model might provide a theoretical and practical tool to understand decision-making in competitive situations for several reasons. NDM focuses on real settings that involve complex problems, time pressure and high stakes. The RPD model might provide theoretical and practical insights about the athlete use of their experiences during high stakes competitive situations. Previous studies from other approaches showed the role of practice in decision-making in simulated or standardized situations (e.g., Raab, 2002), and the use of procedural rules to make decisions in competitive situations (e.g., McPherson \& Kernodle, 2003). The RPD model could provide insights about the number of decisions made by the athletes in competitive situations. Previous studies showed that experts made several decisions before choosing one (e.g., Johnson \& Raab, 2003). NDM could extend knowledge about the information perceived in the course of action that is reported by athletes. 
Previous studies showed that experts reported information that was significant for them (e.g., Hauw \& Durand, 2007) and salient (e.g., Salvesbergh et al., 2002).

This study aimed to test the RPD model in a high-level sports context and elicit relevant features taken into account by athletes during the decision-making process.

\section{Method}

\section{Participants}

Seven male professional level volleyball players participated voluntarily in this study. They ranged in age from 22 to 32 years $(M=25.2$ years, $S D=3.9$ years). They were playing for a club team participating in the first division of the French Championship. They had all practiced volleyball for more than 10 years, apart from one player who had practiced for 9 years. Two players played at international championship level. During the following season, three other players played for the national team.

\section{Data Collection}

Two types of qualitative data were collected at different times. Data were observed and recorded during a competitive match, and data were elicited during self-confrontation interviews.

Data observed and recorded during the competitive match. The recorded match was the return match of the French Championship quarterfinal. It was a qualifying match for the European championships. Seven video cameras were used. One was placed in the stand at the back of the court, in the middle of the court width. The six others were placed on the side of the court, behind the post and the referee's chair. Each of these six cameras recorded the actions of one particular player and his immediate environment. Each cameraman followed one player during the match. When a player was substituted, the cameraman followed the new player. All action time was recorded with cameras stopped only during time outs, when the coach talked to the players, and during change of ends. The researcher took notes about other 
forms of data that were considered important for the study and not recorded by the camera, such as the score corresponding to a substitution.

Data collected during self-confrontation interview. Data were collected during selfconfrontation interviews with each of the seven players who had played the most during the match. They were conducted between the 2nd and the 5th day after the match. The methodology of this type of interview is similar to the first stage of the techniques of stimulated recall used by Omodei et al. (1998). The interviews were based on the video recording of the athletes during the match. The athletes were invited to recall thoughts and feelings associated with what was shown on the screen. The recall process was facilitating by using some non-directive questions. In self-confrontation interviews, each player was confronted by the video of the game with one of the trained researchers. The latter began the tape during the serve and stopped it when the point was finished. The player was invited to comment on his decisions and the events that led up to the decisions. The self-confrontation interview is a method developed by Cranach (von) and Harré (1982) that aims to elicit ongoing cognitions. The athletes were presented with their activity as soon as possible after the recording. Players were asked to describe and explain their own behaviour and activity. The duration of each interview was limited to 90 minutes. Each player was presented with two screens; one contained the video of the match and the second consisted of the interviewed player's actions and his near environment. Players could stop the video at any time to explain something that they deemed important. The interview was structured to elicit information and salient features taken into account by the players during decision-making (Hoffman, Shadbolt, Burton, \& Klein, 1995). The interviewer aimed to lead the athlete to think aloud, just as he had been thinking during the course of action. The player was invited to comment on what he experienced during the course of action. Specific follow up questions were concerned with intention (“What do you want to do here?”), focussing (“What are you looking at?”), thought 
("What are you thinking of?"), and decision conditions ("What's leading you to make this decision?”). Questions did not refer to the result of action. The interviewer led the player to comment on the decision made in the situation they were watching. Some signs indicated that players were reporting from the first person perspective the focus non longer on the screen, their look glazed over, and slower speech (Vermersch, 1996).

\section{Data Processing}

Data recorded during the match were watched to distinguish the situations and the players' actions. Data elicited during the self confrontation-interviews were transcribed verbatim and given to the participants to confirm the validity of transcription. Data were processed in four phases: (a) making short accounts of the situations, (b) analyzing the short accounts according to the RPD model levels, (c) generating categories of salient features taken into account by players during the decision-making process, and (d) comparing the frequencies of salient features considered during decision-making for each level of the RPD model.

The first phase consisted of describing the game context and situations from the video recorded data, noting the score, and indicating the verbal reports from the interview regarding the player's decision. The situations were concerned with the actions and the positions of the player under review, his teammates, his opponents, and the trajectory of the ball, according to each game phase. Descriptions related to the technical language of volleyball (see Table 1). For example, a description consisted of "Paul blocked with Jim on the right of the court. He touched the ball over the net and then defended it down. The setter set.”

The second phase aimed at indicating the level of each situation regarding the RPD model. Verbal reports were analyzed. For example, verbal reports might ask (a) "Could the player assess the situation first or did he need to wait for further information?” (b) "Did the situation evolve in an unexpected way or not?" (c) "Did the player evaluate the action he 
wanted to carry out or not?” According to the RPD model, if the player quickly assessed the situation to decide what to do, then the situation was a simple match (level 1). In this case, critical information was available, the situation seemed familiar to him, so he could rapidly assess it, choose a course of action, and implement it. For example a player said: "maybe he was afraid to hit powerfully, because his arm went down. So my arms went down too" (Table 1). If the player needed more information to assess the situation or if the situation was assessed before evolving in an unexpected way for him, then the player had to diagnose it (level 2). He had to wait for useful information to occur or he had to assess what had changed. For example a receiver said: "I could not see if he had hit the ball well. The trajectory of the ball was powerful". So he had to wait for information regarding the return of the ball. In another example, a defender said: "that's a ball that was deflected by the block, I spent time reacting. I was expecting a powerful return of the ball and suddenly the ball was deflected". The player had to assess the changing situation in a short time frame. If the player mentally simulated the possible result of a course of action to know if it would have worked or not, then he evaluated a course of action (level 3). Thus he chose the course of action that he thought would work. For example, a player said: "If I had hit during my run up, then I probably would have sent the ball out. If I had hit the ball in front of me, then I would have sent it out of bounds. So I changed". When the players reported a mental simulation, they often used a sentence in the form "if... then".

The third phase aimed to generate categories of salient elements noted by the players according to RPD model and specifically to the game of volleyball. We decided to generate categories within the specific domain of volleyball terminology before using the RPD model categories. This approach allowed the context of the decision during the match to be taken into account. Then we compared the generated categories to those of the RPD model. This phase consisted of two steps. The first one was concerned with an inductive analysis of the 
verbal reports to generate categories of the features taken into account by the players to make their decision. This analysis referred to the Grounded Theory (Corbin \& Strauss, 1990). Each category was defined and their content was described to avoid the fact that one element could pertain to two categories. We analyzed the verbal reports separately. We discussed each category until we came to an agreement about them. The second step consisted of a deductive analysis; the generated categories were compared to the categories of the RPD model to test the adequacy of the RPD model in the field of volleyball.

The fourth phase referred to a comparison between the frequencies of the salient features that were reported by the players for each level of the RPD model.

\section{Results}

\section{Making Short Accounts of the Situations}

Seventy short accounts were listed in a table containing three columns: the score, the description of the game situations, and data elicited during the self confrontation interview. As an example, three of the short accounts are reported in table 1.

Analyzing the Short Accounts According to the RPD Model Levels

According to the RPD model, the analysis of the situations reported by the players referred to three levels. Results indicated that 57 situations were recognized rapidly by the players, who could then quickly implement a course of action (level 1). Nine situations were assessed for a longer time (level 2). In four situations, the players mentally simulated the consequences of the course(s) of action to determine if it would have worked or not before implementing one (level 3).

\section{Generating Categories of Salient Features Taken into Account during Decision-making}

This phase was concerned with two steps. The first one consisted of generating the categories of salient features reported by the players and the second one referred to a comparison between generated categories and the categories of the RPD model. Regarding 
the first step, twelve categories were elaborated. They referred to: (a) information about their opponent(s), (b) their teammates(s), and (c) themselves, (d) the trajectory of the ball, (e) their expectation about the players' actions, (f) abilities and tendencies of their opponents, (g), their partners, (h), themselves, (i) the number of decision(s) made, (j) the rules used, (k) a preceding event, and (l) the consequences of a course of action (see Table 2).

Information about the players consisted of the actions or positions on the court of the opponents, the teammates, the player himself. The actions could be concerned with the entire body or with a part of the body. Information about the trajectory of the ball was concerned with the direction of the ball and the possible changes of direction, the power of the hit/serve, and where the ball fell. Expectations consisted of what they thought the players could do in the current situation, they referred to an anticipation about a specific player's action or a particular trajectory of the ball. The abilities and tendencies of their opponents, teammates and themselves consisted of typical actions that were often carried out by a specific player in a typical situation, their level of expertise in specific situations, their role in the team, and their confidence in their teammates. The player made one or several decisions regarding a specific situation. Rules indicated what the player could carry out in typical game situations. They referred to an association between a condition and an action to be carried out. They were in the form "if condition C holds then take action A". A preceding event consisted of a similar situation to the current event which had occurred during the current match or during a prior one. The players compared the current situation and event to prior ones. This comparison led them "to recognize" the situation as typical. The consequences of the course(s) of action were concerned with the possible effects of the action on the development of the situation. The player mentally simulated the possible consequences of an action to decide if it would work or not. Consequences were reported in the form "if I do this, then this will occur". 
Different associations were found between decisions and some relevant features of decision-making (see Table 3). The players reported information about their own actions and positions in all decision-making. They reported most frequently: (a) one goal, (b) rules, (c) opponents' actions, and (d) teammates' action. They less frequently reported: (a) consequences of a course of action, (b) the players' abilities and tendencies (c) expectation about the players' actions. Verbal report analysis indicated that all the salient features reported by the players were linked to their role in the team. For example a hitter said: “To hit in zone 3, I have to line up the setter". His action depended on the type of set he had to hit (e.g., a short and quick set very near to the setter).

The second step of this phase was concerned with the comparison between these formerly generated salient features to the categories of the RPD model. The model suggests that recognition has four by-products: (a) relevant cues, (b) expectancies, (c) plausible goals, and (d) typical action. The results showed that the relevant cues referred to information about the actions and positions of teammates, opponents, the player himself and on the trajectory of the ball (see Table 2). Expectancies were concerned with expectations about the players' actions (i.e., anticipation of a teammate's or an opponent's action) and with the players' abilities and tendencies (i.e., specific focus on the possible actions of the player regarding his abilities and tendencies). The plausible goals were concerned with decisions that they were able to make in any given situation. Players indicated one or two possible decisions. Typical action included both the rules used by the players to make their decision and a preceding event. Rules and preceding events referred to a typical situation and thus to a decision. In a preceding event, the decisions had worked or not. If it had worked, the players reproduced it, if not, it incited them to pay more attention to the development of the situation. For example, a blocker said: "I remember, this situation seems to be like a preceding one, it was a hit from zone 6. I was expecting a hit on the end and the hit occurred in zone 6, so I was in late to 
block. In the current situation, I was expecting a hit to the end too, I was preparing to move and I could already see the ball in zone 6. So I jumped in front of him." In this situation, the blocker prepared to move whilst continuing to look at the trajectory of the ball.

In level 3 of the RPD model, the decision maker considers one action, evaluates it to determine if it will work or not. This assessment consisted of mentally simulating the likely consequences of the course(s) of action. In the present study, the assessment of the course(s) of action was concerned with the consequences of the player's own action or with the consequences of the other players' actions. The consequences appeared in the form "if I do this, then this will happen”. The generated categories of salient features were consistent with the categories of the RPD model. The results showed that the players often utilized a typical action associated with the use of rules or with reference to a preceding event. These results suggested that decisions were partly prearranged before the decision was made. Rules were learned during the training process, and a preceding event led to a choice in the players' decision in a competition situation.

Comparing the Frequencies of the Salient Features Considered during Decision-making for each Level of the RPD Model

The RPD model consists of three levels. The comparison of the frequencies of salient features for each level of the RPD model revealed some similarities and differences between levels (Table 3). At levels 1 and 2, the players more frequently reported: (a) one goal, (b) typical action (more specifically rules), and (c) information about relevant cues. They did not report consequences of a course of action. They less frequently reported expectancies. In level 2, they did not report the players' abilities and tendencies. Whilst in level 3, they more frequently reported consequences of a course of action and relevant cues than other features. They did not report expectation, nor opponents' and teammates' abilities and tendencies. They reported one goal just as frequently several. In levels 1 and 2, the multiple decisions 
were concerned with the development of the situation; the players made a decision, then another to adapt to the changing situation. In level 1, such decisions were made early, and the player did not precisely know what would have happened. For example, a player was preparing to block at the end, while at the same time he was waiting for more information on the situation before moving. When the situation evolved, he abandoned his first decision to adapt to the changed situation. In level 2, the first decision referred to a specific situation and the second decision referred to the sudden and unexpected change in the development of the situation. For example, a player was preparing to defend a power hit in the back of the court when the block deflected the ball, so he dived to the front zone of the court. In levels 1 and 2, the multiple decisions were concerned with the development of the situation; the players made a decision, then another to adapt to the changing situation. In level 3, the multiple decisions were concerned with the outcome of the mental simulation; if they thought the course of action would not work, then they made another decision.

\section{Discussion}

The results of this study showed that the players' decision-making was based both on a process of recognition of a typical situation and on the use of associations between a typical situation and a typical action. The current situation was compared to a typical situation contained in memory. The typical situation was linked to a typical action that had to be adapted to the current situation. The situations were perceived at first as typical or not. If yes, they were simple matched, if not they were diagnosed. Sometimes, the players evaluated the course of action to know if it would have worked or not. Most often, the players reported only one decision. The results suggested that the players used their experience to carry out an action. The findings will be discussed from two perspectives: the results with the RPD model (Klein, 1997) and the updating of their experience. 
In general, the results obtained in this study reinforced the RPD model (Klein, 1997). As the model predicts, the players' decision-making consisted of two steps: situation assessment and a choice of a course of action. A process of recognition of the typicality of the situation permitted the assessment of the situation. This process had four by-products: (a) relevant cues, (b) expectancies, (c) plausible goals, and (d) typical actions. The players perceived relevant cues according to their roles and their functions in the team regarding the situation. These relevant cues were concerned with the trajectory of the ball and with the positions and the specific actions of the teammates, the opponents and the player himself. Expectancies consisted of expectation or anticipation about a specific player's action or possible players' action according to their abilities and tendencies. The players referred to a typical action contained in memory to implement an action; this typical action was linked to specific conditions (i.e. a typical situation). This typical action was concerned with the rules or a preceding event. The players investigated some plausible goals to adapt to the unexpected situation development; this development could be either sudden or progressive. Taking into account all these by-products led the players to recognize the situations as being familiar. This recognition process seemed to depend on their experience of volleyball situations. Most situations were rapidly recognized and classified as level 1.

As the model predicts, when the situations were not perceived as typical at first, the players diagnosed the situation. They had to wait for useful information. For example, a receiver said: "I could not see if he had hit the ball well. The trajectory of the ball was powerful”. Moreover, the player had to be aware of the development of the situation in order to adapt. For example a defender said: "I was expecting a hit to the end and the hit occurred in zone 6 so I was in late to block". The results showed that the players pursued the situation assessment until they carried out their action. This continuing situation assessment led them to adapt their decision to the development of the situation. This continuing assessment 
corresponded well with the concept of situation awareness (Endsley, 1995; Endsley et al. 2003). The environment is continuously assessed to include all new information in the player's decision. Situation assessment appeared to be dynamic and contextual. The players assessed the situations, when this assessment seemed sufficient for the players to act they made a decision while still continuing to assess the situation. Situation assessment appeared to be a continuous process, coupled with the ever-changing environment. Situation assessment could be compared to a process of natural drift; it continues until the operator involved in the situation is satisfied (Amalberti, 2003).

As the RPD model predicts, the players assessed the consequences of their actions to confirm their choice of a particular course of action or not. This assessment aimed to know whether a particular action would work or not. If yes, they implemented it (e.g., "I told myself if I can set high, I know he would cope"); if not, they modified their action (e.g., "if I had hit the ball in front of me, I'd have sent it out of bounds. So I changed and I hit the ball toward the left side"). These results have to be considered with caution, because there were only four decisions in level 3. The results showed that the players took into account the features included in the RPD model. Nevertheless, some features were more frequently reported than others; relevant cues and typical action were more reported than expectancies and several goals. Moreover, most often, the players reported only one goal. This suggests two points. The first point indicates that in volleyball situations, time-pressure is so high that the players do not have enough time to consider several options to implement one of them. To cope with high time-pressure, volleyball players use a game system, which indicates that the players' actions are performed according to their position on the court and to the current game situation. For example, a hitter said: “to hit in zone 3, I've to line up the setter”. The game system contains a set of associations that links typical situations to typical actions (e.g., Blain, 2006). The players' actions appeared to be largely prearranged by the game system and their 
abilities regarding each phase of the game. In high time-pressure conditions, the use of a game system largely limits the relevance of considering other plausible goals. The use of a game system aims to carry out quicker, and implement efficient, decisions. The game system takes into account: (a) rules of the games, (b) typical situations of the game, (c) players' abilities, and (d) players' roles in the team. It could be compared to the Common Frame Of Reference (COFOR) developed by Hoc (2001). This COFOR refers to shared knowledge and shared abilities.

The second point indicates that a particular decision was made with regard to the developing situation. For example, the setter said: “I saw the center blocker was preparing to jump. So I set to the end hitter". In another example, a defender said: "there was a ball that was deflected by the block and I spent time reacting. I was expecting a powerful return of the ball and suddenly the ball was deflected; I'm diving...” In these cases, the players took into account critical elements to make their decision. Such decisions included the position of the center blocker and the deflection of the trajectory of the ball. The players did not report all the information they perceived during the decision-making process. Rather they talked about critical cues regarding the situation that they were describing. These results reinforced the idea that players spend more time assessing what is happening rather than comparing several courses of action (Klein, 1997).

Updating of the Players' Experience

The RPD model aims to describe how agents can use their experience to make decisions without needing to compare the pay-off with the limits of their chosen course of action. Players' experience appeared in: (a) the use of a typical action associated with rules and a preceding event, (b) the focus on critical information, and (c) the anticipation about a particular player's action according to the possible range of actions in a given game situation. Results suggested that players experience had two sources: training and competitions. During 
training, players learn some rules of the game system; they learn to focus their attention on critical cues (e.g., the height of the hitter's arm) and to consider the players' abilities and tendencies. Learning about the opponents' abilities and tendencies consists of observing their opponents during video sequences or during competitions. The coach, who expects the players to pay attention to some typical game phases or to particular opponents' actions, organizes video sequences. This training aimed to develop an efficient actions register (Macquet \& Fleurance, 2006). It contains typical actions, chosen on a technical and a tactical register controlled by the coach. The job of the coach consists of (a) identifying typical problems encountered in the course of the matches, (b) classifying them, and (c) finding solutions that athletes can train with, to be able to use them during competitions. The efficient actions register allows for the development of the game system. The use of rules reinforced the results obtained as shown by Macquet and Fleurance (2006, 2007) and McPherson and Kernodle (2003). The use of training experience reinforced the results obtained as shown by Kibelé (2006), Poolton et al. (2006) and Raab (2002, 2003). Results have shown that athletes acquired experience during the course of the matches also. The athletes memorized given situations to learn about other players and a given game. Players learned from the events that occurred during the match. For example, they observed what happened in a given situation as a consequence of the implementation of a certain course of action. They observed what actions the opponents carried out most often. These results reinforced those of the Sève et al.'s study (2003) about exploration activity of table tennis players. Theories of sport training consider that in competitions, athletes have to reproduce what they have learned during training periods (e.g., Salmela, 1996; Weineck, 1996). However, the present results and the results of Macquet and Fleurance (2007), McPherson and Kernodle (2003), Sève et al. (2003), and Sève and Poizat (2005) showed that players learn during competitions. This factor is not usually taken into account by coaches although it could be. This element of our study could 
contribute to improved decision-making in competitive situations. These results suggest some implications for coaching. The coach could continue to develop and reinforce associations between a typical situation and a typical action to allow players to be more readily efficient in high time-pressure situations. The training process consists of overtraining some actions to reproduce them and also adapting them to the particular context. At the same time, the coach could lead the players to make some other decisions by querying players' abilities and tendencies, and events as they are perceived. A specific framework could be developed, where the players could change roles to become accomplices for the opponent and where they could investigate the game and think about what the opponent could carry out. These two implications refer to the development and the updating of the players' knowledge about the game, suggested in different perspectives (i.e., Macquet \& Fleurance, 2007; McPherson \& Kernodle, 2003; Sève et al., 2003) and to the interpretation of the athlete's particular situation according to salient and significant information (e.g., Arripe-Longueville (d') et al., 2001). They also refer to a perspective concerned with a proactive attitude (Cellier, 1996). Taking into account both the updating of knowledge about the players and the game play also allows players to think about what could happen in a situation in which they are committed. The players expect a particular opponent's action or simulate the consequences of a course of action. Their expectations contribute to investigating a specific course of action while, at the same time, continuing to assess the way that the situation is evolving. If the situation evolves in the expected way, they carry out the action, if not, they diagnose the situation to emphasize its typicality to implement a course of action. Their mental simulation of the consequences of a course of action allows them to adapt their decision more suitably, by anticipating the outcome of their course of action on the game play. Although these simulations were not revealed in most situations, they seemed to allow the players to cope with time pressure and situation complexity in order to be efficient. 
This study presents one limitation. Only seven players had participated in the study. This limits the extent of the results. Despite this limitation, this study and NDM approach provide a framework that enables new insights into athletes' decision-making. It offers new perspectives for sports psychologists to understand volleyball players’ decision-making (and, more generally, athletes' decision-making) during competitive situations. It also offers the possibility for athletes and coaches to question their way of playing, to involve them in a reflexive practice (Schön, 1993). 


\section{References}

Amalberti, R. (2001). La maîtrise des situations dynamiques [Control of dynamic situations]. Psychologie Française, 46, 107-118.

Amalberti, R. (2003). La sécurité écologique et la maîtrise des situations : Concepts et stratégies mis en jeu par les professionnels pour assurer leur propre sécurité et celle du système [Ecological security and situation control : Concepts and strategies used by professionals to ensure their own security and those of the context]. In D. R., Kouabenan, \& M. Dubois (Eds.), Les Risques professionnels: Evolutions des approches, nouvelles perspectives (pp. 73-82). Toulouse: Octares.

Araújo, D., Davids, K., \& Hristovski, R. (2006). The ecological dynamics of decisionmaking in sport. Psychology of Sport and Exercice, 7, 653-676.

Arripe-Longueville (d’), F., Saury, J., Fournier J., \& Durand, M. (2001). Coach-athlete interaction during elite archery competitions : An application of methodological framework used in ergonomics research to sport psychology. Journal of Applied Sport Psychology, 13, 275-299.

Blain, P. (2006). Volley-ball: de l'apprentissage à la compétition de haut niveau [volleyball: From learning to high level competition]. Paris : Vigot.

Cellier, J.- M. (1996). Exigences et gestion temporelle dans les environnements dynamiques [Requirements and time management in dynamic environments]. In J.- M. Cellier, V. De Keyser, \& C. Valot (Eds.), La gestion du temps dans les environnements dynamiques (pp. 19-48). Paris : PUF.

Corbin, J., \& Strauss, A. (1990). Basics of qualitative research: Grounded theory. Procedures and techniques. New-Bury Park, CA: Sage. 
Cranach,(Von) M., \& Harre, R. (1982). The Analysis of Action. Recent Theoretical and Empirical Advances. Cambridge: Cambridge University Press.

Endsley, M. (1995). Toward a theory of situation awareness in dynamic systems. Human Factors, 37, 32-64.

Endsley, M., Bolté, B., \& Jones, D. G. (2003). Designing for situation awareness. London: Taylor \& Francis.

Ericsson, K. A., \& Simon, H. A. (1980). Verbal reports as data. Psychological Review, 87(3), 215-251.

Ericsson, K. A., \& Simon, H. A. (1993). Protocol Analysis. Verbal reports as data. Cambridge: The MIT Press.

Farrow, D., \& Abernethy, B. (2003). Do expertise and the degree of perception-action coupling affect natural anticipatory performance? Perception, 32, 1127-1139.

Hauw, D., \& Durand, M. (2007). Situated analysis of elite trampolinists’ problems in competition using retrospective interviews. Journal of Sport Sciences, 25(2), 173-183.

Hoffman, R. R., Shadbolt, N. R., Burton, M., \& Klein, G. (1995). Eliciting knowledge from experts: A methodological analysis. Organizational Behavior and Human Decision Processes, 62(2), 129-158.

Hoc, J.-M. (2001). A cognitive approach to cooperation in dynamic situations. International Journal Human-Computer studies, 54(4), 509-540.

Johnson, J. G, \& Raab, M. (2003). Take the first: Option-generation and resulting choices. Organizational Behavior and Human Decision Processes, 91, 215-229.

Kaempf, G. L., \& Orasanu, J. (1997). Current and future applications of naturalistic decisionmaking in aviation. In C. E. Zsambok, \& G. Klein (Eds.), Naturalistic Decision-Making (pp. 81-90). Mahwah: Erlbaum. 
Keyser (de), V., \& Nissen, A.-S. (2001). The management of temporal constraints in naturalistic decision-making: The case of anesthesia. In E. Salas, \& G. Klein (Eds.), Linking expertise and Naturalistic Decision-Making (pp. 171-188). Mahwah: Erlbaum.

Kibele A. (2006). Non-consciously controlled decision-making for fast motor reactions in sports- A priming approach for motor responses to non-consciously perceived movement features. Psychology of Sport and Exercise, 7, 591-610.

Klein, G. (1997). The Recognition-Primed Decision model: Looking back, looking forward. In C. E. Zsambok, \& G. Klein (Eds.), Naturalistic Decision-Making (pp. 285- 292). Mahwah: Erlbaum.

Klein, G., Wolf, S., Militello, L., \& Zsambok, C. (1995). Characteristics of skilled option generation in chess. Organizational Behavior and Human Decision Processes, 6, 63-69.

Macquet, A.-C.,\& Fleurance, P. (2006). La prise de décision en sport de haut niveau : Un exemple chez une joueuse experte en badminton [Decision-making in high level sport : A case study in an expert badminton player]. In E. Brangier, C. Kolski, \& J.-R. Ruault (Eds.) ergo-ia Symposium on L'humain comme facteur de performance des systèmes complexes. Bidart : Editions Estia \& Estia innovation.

Macquet, A.-C., \& Fleurance, P. (2007). Naturalistic decision-making in expert badminton players. Ergonomics, 50(9), 1433-1450.

McPherson, S. L., \& Kernodle, M. W. (2003). Tactics, the neglected attribute of expertise. In J. L. Starkes, \& K. A. Ericsson (Eds.) Expert Performance in Sports (pp. 137-168). Champaign, IL: Human Kinetics.

Nisbett, R. E., \& Wilson, T. D. (1977). Telling more than you can know: Verbal reports on mental processes. Psychological Review, 84(3), 231-259. 
Omodei, M. M., McLennan, J., \& Withford, P. (1998). Using a head-mounted video camera and two-stage replay to enhance orienteering performance. International Journal of Sport Psychology, 29, 115-131.

Pascual, R., \& Henderson, S. (1997). Evidence of naturalistic decision-making in military command and control. In C. E. Zsambok, \& G. Klein (Eds.), Naturalistic DecisionMaking (pp. 217-226). Mahwah: Erlbaum.

Poolton, J. M., Masters, R. S. W., \& Maxwell, J. P. (2006). The influence of analogy learning on decision-making in table tennis: Evidence from behavioral data. Psychology of Sport and Exercise, 7, 677-688.

Raab, M. (2002). T-ECHO: Model of decision-making to explain behavior in experiments and simulations under time pressure. Psychology of Sport and Exercise, 3, 151-171.

Raab, M. (2003). Decision-making in sports: Influence of complexity on implicit and explicit learning. International of Sport and Exercise Psychology, 1, 406-433.

Roth. E. M. (1997). Analysis of decision-making in nuclear plant emergencies: An investigation of aided decision-making. In C. E. Zsambok, \& G. Klein (Eds.), Naturalistic Decision-Making (pp. 175-182). Mahwah: Erlbaum.

Salas, E, \& Klein, G. (Eds.) (2001). Linking expertise and Naturalistic Decision-Making. Mahwah: Erlbaum.

Salmela, J. H. (Ed.) (1996). Great job coach! Ottawa, Ontario, Canada: Potentium.

Savelsbergh, G. J. P., Williams, A. M., Van Der Kamp, J., \& Ward, P. (2002). Visual search, anticipation and expertise in soccer goalkeepers. Journal of Sports Sciences, 20, 279-287.

Schön, D. A. (1983). The reflective practitioner: How professionals think in action. NewYork: Basics books.

Sève, C., \& Poizat, G. (2005). Table tennis scoring systems and expert players’ exploration activity. International Journal of Sport Psychology, 36, 320-336. 
Sève, C., Saury, J., Ria, L., \& Durand, M. (2003). Structure of expert players’ activity during competitive interaction in table tennis. Research Quarterly For Exercise and Sport, 74, 71-83.

Simon, H. A. (1956). Rational choice and the structure of the environment. Psychological Review, 63, 129-138.

Theureau, J. (1992). Le Cours d'Action: Analyse Sémio-logique. Essai d'une anthropologie Cognitive située [The Course of Action : Semiological analysis. An essay about situated cognitive anthropology]. Berne: Lang.

Varela, F. J., \& Shear, J. (Eds.) (1999). The view from within: First person approaches to the study of consciousness. Bowling Green, $\mathrm{OH}$ : Academic Press.

Weineck, J. (1996). Manuel d'entraînement [Training manual]. Paris: Editions Vigot.

Williams, A. M, \& Davids, K. (1995). Declarative knowledge in sport: A by-product of experience or a characteristic of expertise? Journal of Sport and Exercise Psychology, 17, 259-275.

Yates, J. F. (2001). “Outsider: Impressions of naturalistic decision-making. In E. Salas, \& G. Klein (Eds.), Linking expertise and Naturalistic Decision-Making (pp. 9-33). Mahwah, NJ: Erlbaum.

Zsambok, C. E., \& Klein, G. (Eds.) (1997). Naturalistic Decision-Making. Mahwah, NJ: Erlbaum. 
Table 1

Examples of Short Accounts of Each of the three Levels

\begin{tabular}{|c|c|c|}
\hline Score & Description of the game situations & Verbal reports from the self confrontation interviews \\
\hline $\begin{array}{l}\text { Set } 1 \\
1-2\end{array}$ & $\begin{array}{l}\text { Paul blocked with Jim on the right of } \\
\text { the court. He touched the ball over } \\
\text { the net and then defended it down. } \\
\text { The setter set. }\end{array}$ & $\begin{array}{l}\text { Paul: "I moved to the end in order to block. I jumped with my } \\
\text { teammate. I was expecting a powered hit. During the jump, } \\
\text { the hitter seemed to change. I saw his arms going down. } \\
\text { Interviewer: What did you think of? } \\
\text { Paul: I don't know. May be he was afraid to hit powerfully } \\
\text { because his arms went down. So my arms went down too. May } \\
\text { be he wanted to achieve a block out. I was afraid, I didn't } \\
\text { want him to succeed. So I adapted my block to his hit and my } \\
\text { arms went down too. } \\
\text { Interviewer: What's lead you to make this decision? } \\
\text { Paul: The fact that the opponent his arms down. I've to look } \\
\text { at the hitter's arm and to "follow" it in order to adapt my } \\
\text { block in order to avoid a block out." }\end{array}$ \\
\hline
\end{tabular}

Set 4 James has served, the opponents

14-7 have spiked, he is trying to receive by diving

(Level 2)

Set 4 Jim received and sent the ball

7-4 between the zones 2 and 3. James was in zone 4 hitting. He moved, went along the attack line and went to the middle of the zone 2 and 3 to jump. He jumped toward the zone 2 . The opponent blockers followed him and he hit between the two opponents.

(Level 3)
James: "I was preparing to defend a hit in the back of the court. There was a ball that was deflected by the block and I spent time reacting. I was expecting a powerful return of the ball and suddenly the ball was deflected by the block. I had to change to adapt to the new trajectory of the ball. It was a short and a curved one. I'm diving but I don't touch the ball. It's an unusual situation.

Interviewer: Do you train this situation?

James: We don't really train to defend a deflected ball, sometimes we face these situations but that's all. Here it wasn't obvious, I was expected a powerful trajectory and at a moment, it was slowed down. It's a question of speed and preparation. If we are ready to receive, then we can react more rapidly."

Jim: "I was preparing to hit taking into account the trajectory of the receive. I began to move when the serve arrived in our court, and in the same time I looked at the serve trajectory. The return moved forward, it didn't come at the middle of the court, near the net. The return arrived at my right, I was in zone 4 and I had to hit between zones 3 and 2. I had a long move to do. If the serve is powerful and the receive is fast, then I've to make a diagonal in order to run up. That generates a problem: some angles are blocked. If I arrive from a diagonal to the setter, I only can hit in front of me, I can't turn myself.

Interviewer: Here the receive is moved forward to the right... Jim: Yes the receive is moved forward to the right, it didn't come at the middle. I had a long move to do. That's the reason I went to the diagonal. If I have had hit during my run up then I probably would have sent the ball out. If I had hit the ball in front of me, I would have sent it out of bounds, so I changed and I hit the ball towards the left side of the court. To hit in zone 3, I have to line up the setter. The setter saw I was a little in late, so he set a short and "slow" ball and I went up with the ball. The opponents' blockers didn't jump on my hit, so it was easier for me." 
Table 3

\section{RPD Model, Salient Features Categories and Verbal Reports}

\begin{tabular}{|c|c|c|}
\hline $\begin{array}{l}\text { Categories of } \\
\text { the RPD model }\end{array}$ & $\begin{array}{l}\text { Categories of salient features elicited } \\
\text { from the verbal reports }\end{array}$ & $\begin{array}{l}\begin{array}{l}\text { Verbal reports from the self confrontation } \\
\text { interview }\end{array} \\
\text { lien }\end{array}$ \\
\hline \multirow[t]{4}{*}{ Relevant cues } & Opponents' actions & $\begin{array}{l}\text { "He’s hitting aiming at his left" } \\
\text { "His arms went down" }\end{array}$ \\
\hline & Teammates’ actions & $\begin{array}{l}\text { "James was well placed at the net" } \\
\text { "The setter set a slow and a short ball" }\end{array}$ \\
\hline & Player's actions & $\begin{array}{l}\text { "I'm trying to counterbalance my arms by closing } \\
\text { the angle..." } \\
\text { "I've called a set very near of me to the center } \\
\text { hitter, in order to move away the end hitters from } \\
\text { the center hitter" }\end{array}$ \\
\hline & The trajectory of the ball & $\begin{array}{l}\text { "that's a ball that was deflected by the block [...] } \\
\text { It was a short and a curve trajectory" } \\
\text { "The receive is moved forward to the right" }\end{array}$ \\
\hline \multirow[t]{4}{*}{ Expectancies } & Expectations & $\begin{array}{l}\text { "I was expecting a powerful return of the ball" } \\
\text { "I was expecting a hit from the end too" }\end{array}$ \\
\hline & Opponents’ abilities and tendencies & $\begin{array}{l}\text { "This guy often hits to his left” } \\
\text { "The setter aimed to set fast balls" }\end{array}$ \\
\hline & Teammates' abilities and tendencies & $\begin{array}{l}\text { "My teammate is a good receiver" } \\
\text { "Our hitter trusts some hitters more than others" }\end{array}$ \\
\hline & Player's abilities and tendencies & $\begin{array}{l}\text { "I'm not the aim receiver" } \\
\text { "The setter often sets me when he's in difficulty" }\end{array}$ \\
\hline Plausible goal & The number of decision(s) made & $\begin{array}{l}\text { "So I set the ball to the end hitter" } \\
\text { "I adapted my block to his hit and my arms went } \\
\text { down" } \\
\text { "I asked myself if I should open the block to open } \\
\text { up a space between my teammate and me in order } \\
\text { to incite him to hit between the two blockers [...] } \\
\text { Therefore, I decided to put pressure on my } \\
\text { teammate" } \\
\text {... "I wanted to block at the end [...] I jumped in } \\
\text { front of him (row line hitter)" }\end{array}$ \\
\hline \multirow[t]{2}{*}{ Typical action } & Rules & $\begin{array}{l}\text { "To hit in zone } 3, \text { I have to line up the setter" } \\
\text { "If the serve is powerful and the receive is fast, } \\
\text { then I've to make a diagonal in order to run up" }\end{array}$ \\
\hline & A preceding event & $\begin{array}{l}\text { "I remember this situation. It seems be like to a } \\
\text { preceding one, it was a hit from zone } 6 \text {. I was a } \\
\text { little similar: I was expecting a hit at the end and } \\
\text { the hit occurred in zone } 6 \text { so I was in late to } \\
\text { block" }\end{array}$ \\
\hline $\begin{array}{l}\text { Consequences of } \\
\text { the course of } \\
\text { action }\end{array}$ & $\begin{array}{l}\text { The consequences of a course of } \\
\text { action }\end{array}$ & $\begin{array}{l}\text { "If I have hit during my run up, I probably would } \\
\text { have sent the ball out" } \\
\text { "If I arrived from a diagonal to the setter, I only } \\
\text { can hit in front of me, I can't turn myself" }\end{array}$ \\
\hline
\end{tabular}


Table 4

Occurrences of Salient Features and their Ratios at the Different Levels

\begin{tabular}{|c|c|c|c|c|c|c|c|c|c|}
\hline \multirow{2}{*}{$\begin{array}{l}\text { RPD model } \\
\text { categories }\end{array}$} & \multirow[t]{2}{*}{ Salient features categories } & \multicolumn{2}{|c|}{ Level 1} & \multicolumn{2}{|c|}{ Level 2} & \multicolumn{2}{|c|}{ Level 3} & \multicolumn{2}{|c|}{ Total } \\
\hline & & $\mathrm{n}$ & ratio & $\mathrm{n}$ & ratio & $\mathrm{n}$ & ratio & $\mathrm{n}$ & ratio \\
\hline \multirow[t]{4}{*}{ Relevant cues } & Opponents’ actions & 37 & 0.65 & 6 & 0.67 & 1 & 0.25 & 44 & 0.63 \\
\hline & Partners' actions & 33 & 0.58 & 5 & 0.55 & 3 & 0.75 & 41 & 0.59 \\
\hline & Player’s actions & 57 & 1 & 9 & 1 & 4 & 1 & 70 & 1 \\
\hline & Trajectory of the ball & 22 & 0.39 & 5 & 0.55 & 1 & 0.25 & 28 & 0.40 \\
\hline \multirow[t]{4}{*}{ Expectancies } & Expectations & 8 & 0.14 & 2 & 0.22 & 0 & 0 & 10 & 0.14 \\
\hline & Opponents' abilities and tend. & 7 & 0.12 & 0 & 0 & 0 & 0 & 7 & 0.10 \\
\hline & Teammates' abilities and tend. & 6 & 0.11 & 0 & 0 & 0 & 0 & 6 & 0.08 \\
\hline & Player's abilities and tend. & 11 & 0.19 & 0 & 0 & 1 & 0.25 & 12 & 0.17 \\
\hline \multirow[t]{2}{*}{ Typical action } & Rules & 42 & 0.74 & 7 & 0.78 & 1 & 0.25 & 50 & 0.71 \\
\hline & Preceding event & 11 & 0.19 & 1 & 0.11 & 1 & 0.25 & 13 & 0.19 \\
\hline \multirow[t]{2}{*}{ Plausible goals } & One goal & 52 & 0.91 & 7 & 0.78 & 2 & 0.5 & 61 & 0.87 \\
\hline & Several goals & 5 & 0.9 & 2 & 0.22 & 2 & 0.5 & 9 & 0.13 \\
\hline Consequences of & Consequences of a course & 0 & 0 & 0 & 0 & 4 & 1 & 4 & 0.06 \\
\hline a course of action & of action & & & & & & & & \\
\hline
\end{tabular}




\section{Acknowledgments}

The author is grateful to the players and to the coach of the volleyball team for their participation to this study. The author acknowledges Philippe Fleurance for his participation in the data processing and the students for their participation in the video recording.

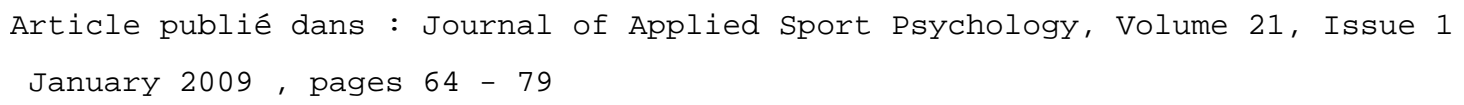

